\title{
A procedure for the evaluation of debris flow stratification
}

\author{
E. Larcan, S. Mambretti \& M. Pulecchi \\ DIIAR - Politecnico di Milano, Italy
}

\begin{abstract}
An experimental campaign (almost 80 tests in a rectangular flume closed by a sluice gate, setting the bed slope at $15^{\circ}$ and $20^{\circ}$ and adjusting the initial solid volume fraction from 0.1 to 0.5 ) was performed at the laboratory of the Politecnico di Milano. The aim of the tests was to assess the propagation of a dam-break wave of a hyperconcentrated mixture of water and granular material, and they showed that a stratification in the flow sometimes occurs. Indeed, depending on the bed slope and on the solid volume fraction in the mixture, in the upper part of the debris flow a layer of clear water may be present on top of an homogeneous layer containing both solid and fluid phases. Hence, a correct mathematical modelling of the phenomenon should account for this key feature and treat the mixture as a full two-phase system. Required for this purpose is a criterion for evaluating the saturation degree of the mixture. A dimensional analysis determined that the solid volume fraction and a Froude number are the fundamental parameters governing the dynamics of the level of the surface dividing clear water and fully saturated mixture. The paper also presents the preliminary results of an analysis using an edge detection algorithm in order to obtain the free surface depth and the depth of the fully saturated layer.
\end{abstract}

Keywords: mature and immature debris flow, two phases models.

\section{Introduction}

A number of models to describe debris flow propagation assume that the solid/liquid mixture is a one-phase fluid, of which it is necessary to define the rehologic equation.

A more realistic description of the phenomenon would require consideration of the mixture as a two-phase fluid. In the literature, quasi two-phase models are 
often used in order to focus on the erosion and deposition phenomena related to the solid phase which are present during the debris flow propagation and which change the solid concentration and, as a consequence, its rehological proprieties [Brufau et al. [3], Zanuttigh and Lamberti [11], Iverson et al.[4], Iverson [5] Whipple [6].

In the case of the granular solid mixture especially, this description is not sufficiently precise, and it is necessary to use a completely two-phase model which enables due account to be taken of the different velocities of the liquid and solid phases (Larcan et al. forthcoming). In this model, however, it is necessary to impose the quite strict hypothesis of mature debris flow.

In the real world, debris flows are often immature: the solid/liquid mixture is present in the lower layer, while only the water is present in the upper one. Other authors have identified the plug flow regime (Armanini et al. [1]), which is not considered here, because it has never been observed in the experimental tests carried out in our Hydraulic Laboratory at the Politecnico di Milano.

The paper presents the results of an investigation carried out to determine the link between the flow nature (mature or immature debris flow) and the flow characteristics. Starting from literature procedures, analysis of the experimental results gave rise to a criterion for determination of the flow type recorded in a rectangular channel following a dam-break phenomenon.

Moreover, preliminary results of an edge detection algorithm are presented.

\section{Experimental set-up}

As described in a previous paper (Larcan et al. [9]), the experimental set-up consisted of a loading tank (dimensions 54 × 50 × $90 \mathrm{~cm}$ ) with a downstream wall made of a sluice gate with pneumatic control and a very short opening time $(0.6 \mathrm{~s})$. The mixture flowed in a $6 \mathrm{~m}$ long channel of rectangular section (height $=50 \mathrm{~cm}$ and base $=54 \mathrm{~cm}$ ). To enable camera recordings, one of the flume lateral walls contained glass windows.

Experimental tests were performed by changing the channel slope, the bottom roughness (smooth bottom made of galvanized plate or rough bottom covered with an homogeneous layer of gravel $\mathrm{d}_{50}=5 \mathrm{~mm}$ ), the solid material characteristics (gravel: $\rho=2621 \mathrm{~kg} / \mathrm{m}^{3} ; d_{50}=5 \mathrm{~mm} ; d_{60} / d_{10}=1.3 ; \varphi=30^{0}$ ), and the volumetric concentration of the solid material in the mixture.

Recordings were made with a Sony Digital Handcam, model DCR-TRV32E camera, which had an acquisition velocity of 25 frames per second, and was electronically elaborated.

Table 1 reports the list of the experimental tests which could be used, thanks to the clarity of images, to test the proposed separation criteria between mature and immature debris flow. In particular, all the parts of each run which allowed a clear reading of the pictures, and thus of the mixture's behaviour in its different phases, were used. As a consequence, the same run could be used to assess front, body or end of the wave characteristics, while other runs were discharged because they were unclear. 
Table 1: $\quad$ Tests used to verify the mature/immature separation criterion.

\begin{tabular}{|ccc|}
\hline $\begin{array}{c}\text { Channel } \\
\text { slope }\end{array}$ & $\begin{array}{c}\text { Channel } \\
\text { bottom }\end{array}$ & $\begin{array}{c}\text { Concentration } \\
(\%)\end{array}$ \\
\hline $15^{\circ}$ & $\begin{array}{c}\text { Smooth } \\
\text { Rough }\end{array}$ & $\begin{array}{c}20,40,60 \\
20,40,60\end{array}$ \\
\hline $20^{\circ}$ & $\begin{array}{c}\text { Smooth } \\
\text { Rough }\end{array}$ & $\begin{array}{c}20,40,60 \\
20,40\end{array}$ \\
\hline
\end{tabular}

\section{Evaluations with a literature model}

Takahashi [10] has suggested distinguishing mature and immature debris flow by means of a criterion based on the hypothesis of equality between the shear velocity and the settling velocity of the particles. This criterion requires the calibration of a generic function of solid particles velocity and diameter. As a consequence, the criterion proposed is empirical. Reporting experimental data in a graph with the non dimensional parameter $h / d$ (where $h$ is water depth and $d$ the solid particle characteristic diameter) on the $\mathrm{X}$-axis, and on the $\mathrm{Y}$-axis the non dimensional parameter $\frac{\sin \vartheta}{\left(\rho_{s} / \rho\right)-1}$ (where $\vartheta$ is the channel slope, $\rho_{S}$ the solid material density and $\rho$ water density), Takahashi finds that immature debris flow occurs when $\frac{\sin \vartheta}{\left(\rho_{s} / \rho\right)-1}<0.15$.

To be noted is that in our laboratory tests the above parameter was equal to 0.16 when $\vartheta=15^{\circ}$, and it was equal to 0.21 when $\vartheta=20^{\circ}$. As a consequence, the observed debris flows should always have been mature.

The shortcoming of Takahashi's procedure consisted in the data used for its calibration, which were taken in uniform or steady flow.

Clearly to be observed in our tests, which simulated the debris flow propagation after a dam break, was a first phase where only water was present, then a second phase where the debris flow could be considered mature, and eventually a third phase where the debris flow became immature, with a lower layer consisting of a mixture of water and solid material moving with low velocity, while clear water (without solid material) moved in the upper layer at a faster rate than the mixture.

This behaviour obviously could not be predicted with Takahashi's criterion, which uses parameters that do not change during the flow propagation: the channel slope is constant for each test, the debris flow height does not change significantly during the different phases analyzed (uniform flow); whereas the mixture concentration may be an important parameter (and it will be again considered below) but is difficult to evaluate. 
It therefore seemed reasonable to substitute the channel slope $\vartheta$ (which is constant in each test) with the slope of the free surface, which changed in space and time. However, the results obtained were unsatisfactory, as shown in Figure 1, where the position of experimental points shows absolutely no trend.

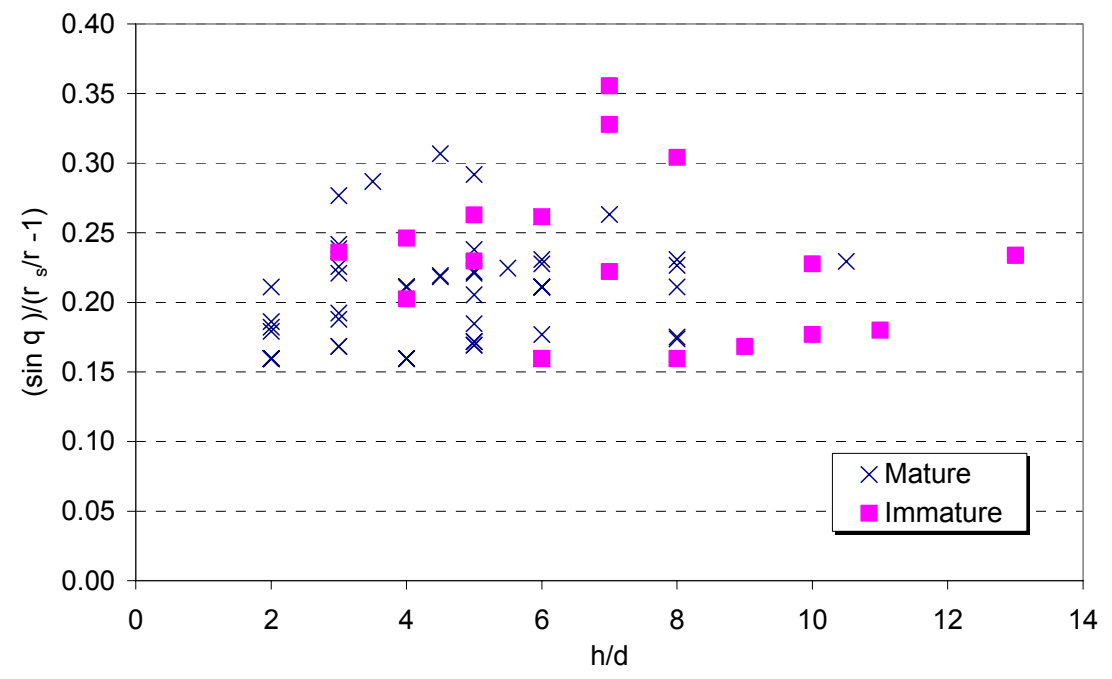

Figure 1: Position of the experimental points found by the authors' tests on Takahashi's diagram.

\section{The criterion proposed}

The unsatisfactory results obtained from application of the original and modified versions of Takahashi's criterion application suggested that this approach should be discarded for a new one based on the relation among concentration, flow velocity and channel slope. For high slopes, and above a given threshold concentration value, mature debris flow was expected. Conversely, for lower channel slopes and low velocities, immature debris flow were expected, while on increasing the debris flow velocity the flow again became mature.

In what follows, we try to analyse how this behaviour can be expressed, looking at the experimental data. However, we would stress some limitations of the data on which the proposed criterion will be tested. To be borne in mind, in particular, is the variability of the concentration during the various propagation phases due to the solid material deposition, which occurred especially in the case of higher concentrations and when the channel bottom was rough.

Because the experimental set-up did not allow evaluation of the concentration variability, this was estimated using a non-stratified two-phase numerical model developed by the authors. This model was based on the classic De Saint Venant equations, taking account of different velocities between the solid and liquid 
phases, and using an erosion and deposition model (Egashira and Ashida [7], modified following the proposals of Ghilardi et al. [8]).

This model is rigorously valid for non-stratified (mature) debris flow only; however, its use seems preferable to the hypothesis of constant concentration equal to that in the loading tank. The same model also gives a Froude number evaluation.

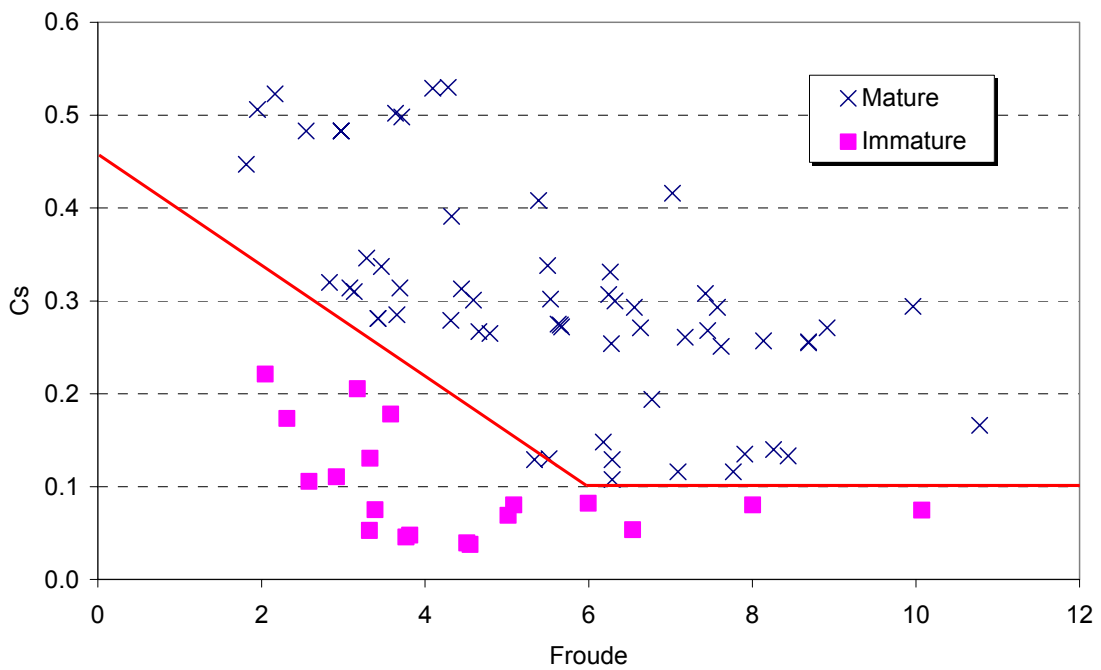

Figure 2: Position of the experimental points found by the authors' tests on the proposed diagram.

Table 2: Comparison between the velocities measured and those computed with the model.

\begin{tabular}{llcc|c} 
& & $\begin{array}{c}\text { Experimental } \\
\text { velocity } \\
(\mathrm{m} / \mathrm{s})\end{array}$ & $\begin{array}{c}\text { Model } \\
\text { velocity } \\
(\mathrm{m} / \mathrm{s})\end{array}$ & Error \\
\hline \multirow{3}{*}{ Slope $15^{\circ}$} & Conc. $20 \%$ & 2.50 & 2.76 & 9.4 \\
& Conc. $40 \%$ & 2.50 & 2.59 & 3.5 \\
& Conc. $60 \%$ & 2.50 & 1.99 & -25.0 \\
\hline \multirow{3}{*}{ Slope $20^{\circ}$} & Conc. $20 \%$ & 3.33 & 3.00 & -11.0 \\
& Conc. $40 \%$ & 2.50 & 2.72 & 8.0 \\
& Conc. $60 \%$ & 2.14 & 2.33 & 8.0
\end{tabular}

Table 2 shows a comparison between the velocities of the front of the wave measured by the recordings (the only ones possible to measure in our tests) and the velocities obtained from the numerical model. It will be seen that the match is quite good; so that the velocity data missing for computation of the Froude number were deduced from the numerical model. 
Figure 2 shows the consistency of the results obtained with the abovementioned hypothesis. The figure also depicts a proposed boundary between mature and immature debris flows.

More tests are needed to confirm the proposed criterion.

\section{Image analysis and automatic detection of debris flow characteristics}

An automatic approach was used to accelerate analysis of the images and to increase their number and reliability.

For this purpose, a computing algorithm to determine the space/time coordinates of the debris flow free surface in the experimental channel has been developed (Bonicchio and Carubelli [2]).

When this computing algorithm has been calibrated with spatial and temporal references, it takes each photogram and transforms it into a grey scale image, to which a filter is applied in order to identify the boundaries. By means of a differing threshold edge detection procedure, this produces a pair of binary images which represent, in the case of immature debris flow, the free surface of the flow and the surface of the mixture layer respectively. Obviously, in the case of mature debris flow, the procedure depicts the profile of only the free surface.

The use of filters based on statistical considerations allowed the elimination of errors caused, for instance, by surface turbulences or brightness variations within the flow. The final output of the program was a text file reporting the space/time coordinates of the two profiles during flow propagation.

With respect to the manual procedure, the temporal density of the data was still limited by the camera acquisition velocity, while the spatial density of the data, previously restricted to sections $20 \mathrm{~cm}$ distant from each other, was now limited only by the camera definition, and in this case can be estimated at around $2.5 \mathrm{~cm}$.

By way of example, Figure 3 shows a result from application of the algorithm, which evidences its reliability.

The procedure described certainly requires further development, for instance in relation to the choice of the mathematical criterion on which the edge detection procedure is based, as well as definition of spatial and temporal references through which images are related to the real experimental conditions. Closer attention should be paid to definition of the threshold parameters used by the algorithm to filter the image and highlight the boundaries of interest. Accurate determination of these values when varying experimental conditions, like the lights, the solid material type, and the channel wall colour, will considerably improve the capabilities of the software and the quality of the data.

Use of the algorithm will greatly accelerate processing of the images, while also allowing rapid experimental data collection, thereby increasing the data available for verification of the mature and immature separation criterion proposed here. 


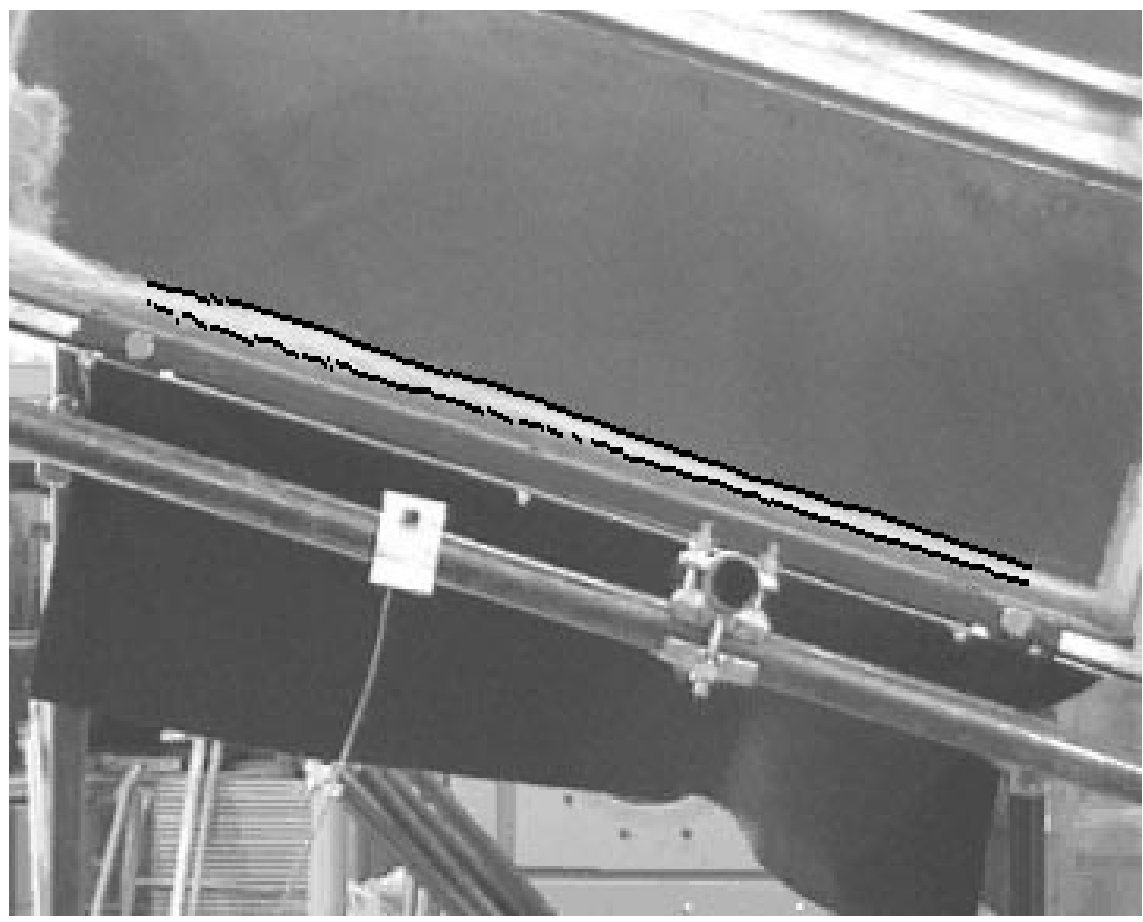

Figure 3: A picture of the debris flow, with the detected profiles superimposed.

\section{Conclusions}

Determining the maturity or immaturity of a debris flow is of great importance in propagation modelling when complete two-phase models are used.

The paper has first tested Takahashi's criterion with experimental data obtained in our laboratory by simulating dam-break conditions. Since this criterion proved unsatisfactory, probably because it was developed under the hypothesis of uniform flow, we modified it by using a free surface slope instead of the slope of the experimental channel. In this case, too, the results were not satisfactory.

Analysis of the experimental results suggested a new empirical criterion, graphically expressed, which, however, requires wider experimental confirmation.

With a view to accelerating data collection and processing, the paper has also outlined the results obtained with a software able to recognize, automatically and with good reliability, the layers in the debris flow. 


\section{References}

[1] Armanini A, Capart H, Fraccarollo L, Larcher M: Rheological stratification in experimental free-surface flows of granular-liquid mixtures. Journal of Fluid Mechanics 532: 269-319 Jun 102005

[2] Bonicchio M., Carubelli A.: Analisi delle immagini e riconoscimento automatico di una colata detritica in una canaletta sperimentale, Tesi di Laurea, Politecnico di Milano, 2004 (in Italian)

[3] Brufau P, Garcia-Navarro P, Ghilardi P, Natale L, Savi F Source: 1D Mathematical modelling of debris flow. Journal of Hydraulic Research 38 (6): 435-446 2000

[4] Iverson RM, Vallance JW: New views of granular mass flows. Geology 29 (2): 115-118 Feb 2001

[5] Iverson RM: The physics of debris flows. Reviews of Geophysics 35 (3): 245-296 Aug 1997

[6] Whipple KX: Open-channel flow of Bingham fluids: Applications in debris-flow research. Journal of Geology 105 (2): 243-262 Mar 1997

[7] Egashira S., Ashida K.: Sediment transport in steep slope flumes, Proc. of RoC Japan Joint Seminar on Water Resources, 1987

[8] Ghilardi P., Natale L., Savi F.: Two mathematical models simulating a real-world debris-flow, Proc.IAHR Symposium on "River, Coastal and Estuarine Morphodynamics", Genova, 1999

[9] Larcan E., Mambretti S., Orsi E.: Leggi di resistenza al moto nelle colate di detriti conseguenti al crollo di dighe. 1. Apparato sperimentale e primi risultati. $28^{\circ}$ Convegno di Idraulica e Costruzioni Idrauliche, Potenza, 16 -19 settembre 2002 (in Italian)

[10] Takahashi T. Debris flow IAHR Monograph Series, Balkema, Rotterdam, 1991

[11] Zanuttigh B, Lamberti A: Analysis of debris wave development with onedimensional shallow-water equations. Journal of Hydraulic Engineering ASCE 130 (4): 293-304 Apr 2004 